\title{
Notes on Estate Taxes, Redistribution, and the Concept of Balanced Growth Path Incidence
}

\section{Joseph E. Stiglitz}

Oxford University

\begin{abstract}
This paper shows that, because of capital accumulation effects, the estate tax may increase inequality of income and wealth. If the government takes actions to offset these accumulation effects, the tax will lead to an increase in equality of income and wealth. More generally, the paper argues that to evaluate the incidence of a tax in a growth context, one should compare policy changes which leave the aggregate capital labor ratio unchanged; we call this balanced growth incidence. But even with the capital labor ratio remaining unchanged, the estate tax may increase inequality in the distribution of consumption.
\end{abstract}

\section{Introduction}

The object of this paper is to introduce a new kind of incidence analysis, which I refer to as balanced growth path incidence, and to apply this concept to the analysis of the effects of estate taxation on the distribution of wealth, income, and consumption. I argue that using conventional approaches to the analysis of the effects of such a tax is likely to lead to misleading conclusions. More precisely, I argue that, because of capital accumulation effects, the estate tax may not achieve the objective to which it is presumably directed, that is, equalizing the distribution of income; if the government takes actions to offset these accumulation effects, the tax will lead to an increase in equality of income and wealth. The desirability of the estate tax may still be questioned, not only because of the distortions which it introduces but also because it may actually increase inequality in the distribution of consumption.

Paper presented to NSF-NBER conference on income taxation, Stanford, California, January 1976. The basic results of Section V were presented at the San Francisco meeting of the Econometric Society, December 1967, as part of a more general study, "The Distribution of Income and Wealth among Individuals." The analysis of Section VII has been greatly influenced by discussions with David Bevan.

[Journal of Political Economy, 1978, vol. 86, no. 2, pt. 2 ]

(C) 1978 by The University of Chicago. $0022-3808 / 78 / 8622-0007 \$ 01.23$ 


\section{Capital Accumulation and Inequality}

The reason that the estate tax may not increase the equality of income is the following: ${ }^{1}$ the estate tax may reduce savings; the reduction in savings and capital accumulation will, in the long run, lead to a lower capital labor ratio; and the lower capital labor ratio will, if the elasticity of substitution between capital and labor is less than unity, lead to an increase in the share of capital. Since income from capital is more unequally distributed than is labor income, the increase in the proportion of income accruing to capital may increase the total inequality of income. This result hinges on three key assumptions (besides the assumption that the elasticity of substitution be less than unity).

\section{Estate Taxes and Savings}

The first assumption in the above argument is that the estate tax leads to a reduction in savings. There are two aspects to this. First, the estate tax can be thought of as a transfer from the individuals who would have inherited the wealth to the population as a whole. The latter is effected, for instance, by the reduction in income tax which the revenues raised through the estate tax allows. The question is, What is the effect of this transfer?

The increased income to the population as a whole will have associated with it the conventional marginal propensity to consume out of income. The effect of the transfer depends on the magnitude of the marginal propensity to consume out of income relative to the marginal propensity to consume out of inheritances. If the latter is treated like any other wealth (rather than like any other income), as seems likely, then since the marginal propensity to consume out of wealth is much lower than that out of income, the estate tax has a significant effect on the aggregate consumption rate.

The second aspect is concerned with incentive effects. If bequests are treated like consumption the $n+1$ st period of the individual's life (where the individual lives $n$ periods), then there is an income effect and a substitution effect associated with the tax. The income effect leads the individual to consume less during his lifetime, the substitution effect to consume more. On a priori grounds it is not possible to say which effect is stronger. But even if the individual is induced to consume less to increase his gross bequest (so that his net bequest is reduced by less than the magnitude of the tax), it does not seem likely that this effect will overcome the transfer effect described above.

\footnotetext{
${ }^{1}$ Further reasons why an estate tax might increase long-run inequality are set forth in Section VIII below and in Stiglitz (1977).
} 


\section{The Concept of Balanced Growth Incidence}

The second assumption in the argument that the estate tax may lead to greater inequality because of reduced savings is that the government does not or cannot take countervailing actions. Presumably, the government through monetary policy could offset any effect on the pattern of capital accumulation.

The question raised here is of import for more than just the analysis of the estate tax. A wide variety of taxes affects savings, and the question is, in a general equilibrium context, How are we to evaluate such taxes? The questions raised are analogous to how we are to evaluate the incidence of a tax in the context of the standard macroeconomic model, for the tax will have a deflationary effect on the economy so that the equilibrium level of national income will be reduced. There is now widespread agreement that the most meaningful comparisons are among policies which leave the level of output constant; for example, we substitute one tax for another tax.

Here it seems to me appropriate to introduce some notion of balanced growth path incidence, where we compare policy changes which leave the aggregate capital labor ratio unchanged. There are a number of such policies: (a) an interest subsidy on savings (essentially substituting lifecycle savings for inheritance savings); $(b)$ offsetting the reduced private savings by increased government savings; $(c)$ reducing social security payments, which again would induce more life-cycle savings; $(d)$ using monetary and debt policy to increase the rate of return on capital and thus increase savings.

\section{The Distribution of Wealth}

The third basic assumption in my argument that the estate tax might increase the inequality of income is that capital is more unequally distributed than labor. Although this is undoubtedly true at the present time, the question may legitimately be raised of whether this would be the case if we had larger inheritance taxes. The answer depends on the particular theory of the determination of the income and wealth distribution. I now show that, indeed, the inheritance tax may have an effect on the equilibrium distribution of wealth, but even if the estate tax has no effect on the aggregate capital labor ratio, it may increase the inequality of consumption.

The argument is presented in a model which is a modification of that presented by Stiglitz (1969). We assume that $(a)$ individuals leave as a bequest to their children what they inherited plus an amount which is a linear function of their lifetime income, $B(t)=s Y(t)-a+B(t-1)$, where $B$ is the bequest and $s$ is the marginal propensity to save out of 
lifetime income; $a \geq 0$ is the intercept of the consumption function (consumption at zero income). Lifetime income for the $i$ th family is equal to their wage income plus interest income, that is, $Y_{i}=w_{i} L_{i}+r C_{i}$, where $C_{i}$ is the amount of (inherited) capital of the family $\left[C_{i}(t) \equiv B_{i}(t-1)\right], w_{i}$ is the wage received, $r$ the rate of interest, and $L_{i}$ is the number of wage earners in the family. $(b)$ Individuals differ in productivity, but the productivity of children is identical to the productivity of their parents (the assumption of perfect correlation of abilities). (c) All families reproduce at the same rate. In continuous time, we let $n$ be the rate of increase in the size of the family. (d) Parents divide their wealth equally among their children.

If we let $y_{i}$ be income per capita in the family and $c_{i}$ be wealth per capita and represent the dynamics of capital accumulation of the family in continuous time, we obtain

$$
\dot{c}_{i}=s w_{i}-a+(s r-n) c_{i}
$$

or, in equilibrium,

$$
c_{i}=\frac{s w_{i}-a}{n-s r}
$$

Thus, the coefficient of variation of wealth, $\gamma_{c}$, is given by

$$
\gamma_{c}^{2}=\frac{E\left(c_{i}-\bar{c}\right)^{2}}{\bar{c}^{2}}=\frac{s^{2} \sigma_{w}^{2}}{(s \bar{w}-a)^{2}}
$$

where $\sigma_{w}^{2}$ is the variance of $w$, and $\bar{w}$ is the mean of $w$. To obtain this result, we observe that in equilibrium, if $p_{i}$ is the proportion of the population in the $i$ th group,

$$
k \equiv \bar{c} \equiv \sum p_{i} c_{i}=\frac{s \bar{w}-a}{n-s r}
$$

where $\bar{c}$ is the average per capita capital. (In this formulation, there is no capital arising from savings within a lifetime [life-cycle savings]; the model can, however, easily be extended to that case.)

If we let $\gamma_{w}$ be the coefficient of variation of (lifetime) wages, and if $a=0, \gamma_{c}=\gamma_{w}$. The dispersion of capital and wages is identical. If $a>0, \gamma_{c}>\gamma_{w}$, capital is distributed more unequally than wages. Since

$$
y_{i}=w_{i}+r c_{i}=\frac{n w_{i}-a r}{n-s r},
$$




$$
\begin{aligned}
\gamma_{y}^{2} & =\frac{n^{2}}{(n-s r)^{2}} \frac{\sigma_{w}^{2}}{\bar{y}^{2}} \\
& =\left(\frac{n}{n-s r}\right)^{2} \gamma_{w}^{2} \alpha^{2} \\
& =\left[\frac{(s y-a)}{s w-a} \alpha\right]^{2} \gamma_{w}^{2} \\
& =\gamma_{w}^{2} \text { if } a=0,
\end{aligned}
$$

where $\alpha=$ share of labor. If $a=0$, inheritance has no effect on the inequality of consumption.

We now impose an inheritance tax, distributing the proceeds as income transfers; if $\tau$ is the tax rate, the wealth-accumulation equation becomes

and

$$
\dot{c}_{i}=\left(s w_{i}-a+s r c_{i}+s \tau k\right)-(n+\tau) c_{i},
$$

$$
\dot{k}=s \bar{w}-a+s(r+\tau) k-(n+\tau) k .
$$

Thus, in long-run equilibrium,

$$
\begin{gathered}
c_{i}=\frac{s w_{i}-a+s \tau k}{n+\tau-s r} \\
k=\frac{s \bar{w}-a}{n-s r+\tau(1-s)},
\end{gathered}
$$

or $k[n+\tau(1-s)]=s y(k)-a$, where $y \equiv w+r k=f(k)=$ output per capita, where $f$ is the (per capita) production function, $f^{\prime}>0$, $f^{\prime \prime}<0$. Hence,

$$
\frac{d k}{d \tau_{\mid s}}=\frac{(1-s) k}{s y^{\prime}-(s y / k)+(a / k)}=-\frac{(1-s) k^{2}}{s \bar{w}-a} .
$$

Even if $s$ were constant (there were no incentive effect), capital accumulation would be reduced. ${ }^{2}$

As a consequence, even though if $k$ were constant inequality of wealth would be reduced, $k$ is not constant, so the effect of inheritance taxation will depend on the elasticity of substitution.

Assume that individuals differ from each other in a Harrod neutral manner, so that $\gamma_{w}$, the coefficient of variation of wages, is a constant with taxation,

$$
\gamma_{c}^{2}=\frac{s^{2} \bar{w}^{2} \gamma_{w}^{2}}{(s \bar{w}-a+s \tau k)^{2}}
$$

${ }^{2}$ Stability of (7) requires $n+\tau>s r$, and stability of (8) implies $n-s r+\tau(1-s)>$ 0 , or, since $k>0, s \bar{w}>a$. 


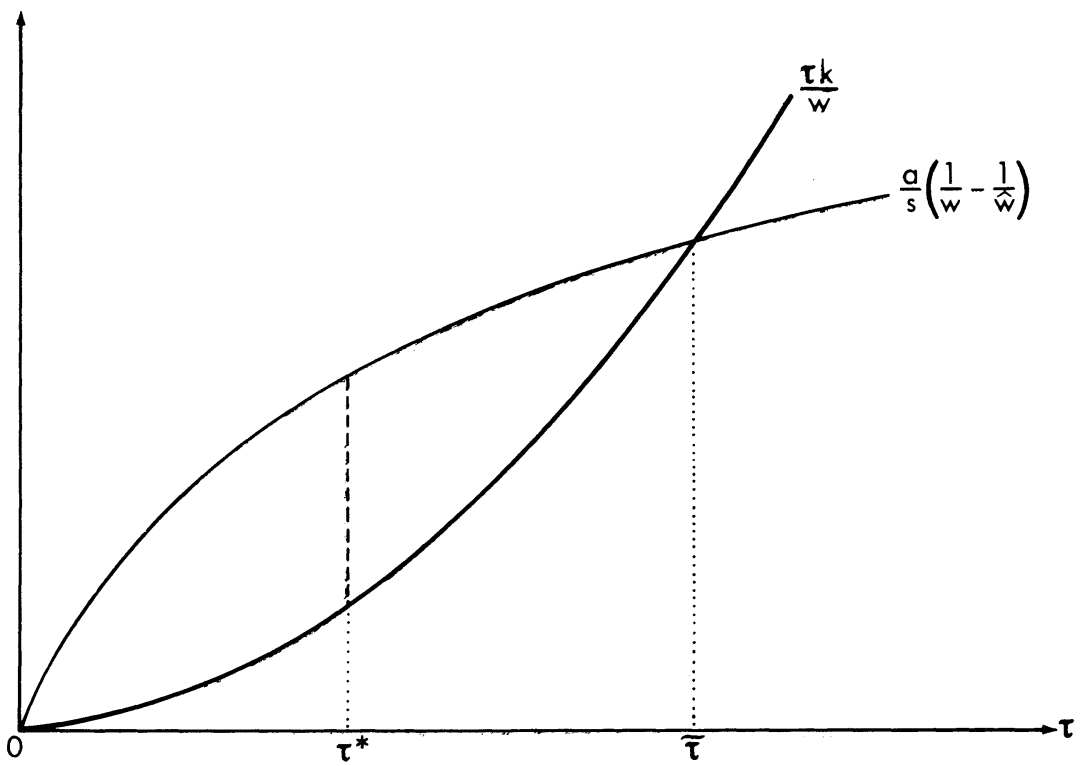

Fig. 1-Inequality at $\tilde{\tau}$ same as at $\tau=0 ; \tau^{*}$ minimizes inequality of wealth $\tilde{w}$ value of $w$ at $\tau=0$.

Thus,

$$
\frac{d \gamma_{c}}{d \tau} \gtrless 0 \quad \text { as } \quad \frac{d[(\tau k / \bar{w})-(a / s \bar{\omega})]}{d \tau} \lessgtr 0 .
$$

In figure $1 \mathrm{I}$ have plotted $\tau k / \bar{w}$ and $a / s \bar{w}$ as a function of $\tau$. Note that as $\tau$ increases, $k$ decreases, the wage decreases, and hence $a / s \bar{w}$ increases. It is immediate that for sufficiently large tax rates inequality must be increased (although for small tax rates inequality may be reduced). Inequality is reduced with an increase in tax rate so long as

$$
\begin{aligned}
\frac{d[(\tau k / \bar{w}-(a / s \bar{w})]}{d \tau} & =\frac{k}{\overline{\bar{w}}}-\frac{(1-s) k^{2}}{s \bar{w}-a}\left[\frac{\tau}{\overline{\bar{w}}}+\left(\frac{\tau k}{\overline{\bar{w}}}-\frac{a}{s \bar{w}}\right) \frac{k f^{\prime \prime}}{\overline{\bar{w}}}\right] \\
& =\frac{k}{\overline{\bar{w}}}\left\{1-\frac{(1-s)}{n+\tau(1-s)-s r}\left[\tau-\left(\tau k-\frac{a}{s}\right) \frac{r}{f \sigma}\right]\right\},
\end{aligned}
$$

$$
>0 \text {, }
$$

where $\sigma=$ elasticity of substitution $=-f^{\prime}\left(f-k f^{\prime}\right) / f^{\prime \prime} k$, or

$$
r<\frac{[\tau(1-\alpha) / \sigma]+(n / 1-s)}{(a / s f \sigma)+s /(1-s)} .
$$


Since

$$
\begin{gathered}
y_{i}=w_{i}=r c_{i}=\frac{w_{i}(n+\tau)-r(a-s \tau k)}{n+\tau-s r}, \\
\gamma_{y}^{z}=\gamma_{w}^{2}\left[\frac{\bar{w}(n+\tau)}{\bar{w}(n+\tau)-r(a-s \tau k)}\right]^{z} .
\end{gathered}
$$

Hence, inheritance taxation increases equality if

$$
\begin{gathered}
\frac{d\{[s \tau(1-\alpha)] /[(n+\tau) \alpha]-\operatorname{ar} /[\bar{w}(n+\tau)]\}}{d \tau}= \\
{\left[\frac{s n(1-\alpha)}{\alpha}+\frac{a r}{\bar{w}}\right] \frac{1}{(n+\tau)^{2}}-\frac{1}{n-s r+\tau(1-s)} \cdot \frac{1-\alpha}{\alpha} .} \\
\frac{1-s}{n+\tau}\left[\frac{a}{k}+\left(1-\frac{1}{\sigma}\right)\left(s \tau-\frac{a}{k}\right)\right]>0 .
\end{gathered}
$$

Figure 2 plots $[s \tau(1-\alpha)] /[\alpha(n+\tau)]-a \tau /[w(n+\tau)]$ as a function of $\tau$. At $\tau=0$, inequality increases if

$$
\sigma<\frac{a / k(1-s)}{(s n+a \mid k)(n-s r)} .
$$

The tax rate which minimizes inequality can also be calculated from (17). The inequality-minimizing tax rate is shown in figure 2. For small values of the elasticity substitution, inequality will increase as $\tau$ increases.

Note that $I$ have in this analysis ignored the possible decrease in the savings rate(s) as a result of the imposition of the tax. That is, the total effects with which we have been concerned are those arising from the reduction in the aggregate savings rate from transferring "capital" to "income"; if $s$ is reduced, as it may well be, the possibility of an inheritance tax increasing inequality is even greater.

Assume, on the other hand, that $s$ changes to keep $k$ constant. From (11) we know that this requires

$$
\frac{d s}{d \tau_{\mid k}}=\frac{(1-s) k}{y+\tau k}
$$

Hence,

$$
\frac{d \gamma_{c}}{d \tau_{\mid k}} \gtrless 0 \text { as } \frac{d[(\tau k / \bar{w})-(a / s \bar{w})]}{d \tau} \lessgtr 0, \frac{d[(\tau k / \bar{w})-a / s \bar{w})}{d \tau},
$$

but

$$
\frac{d[(\tau k / \bar{w}-(a / s \bar{w})]}{d \tau}=\frac{k}{\bar{w}}+\frac{a}{\bar{w} s^{2}} \frac{d s}{d \tau}>0 .
$$



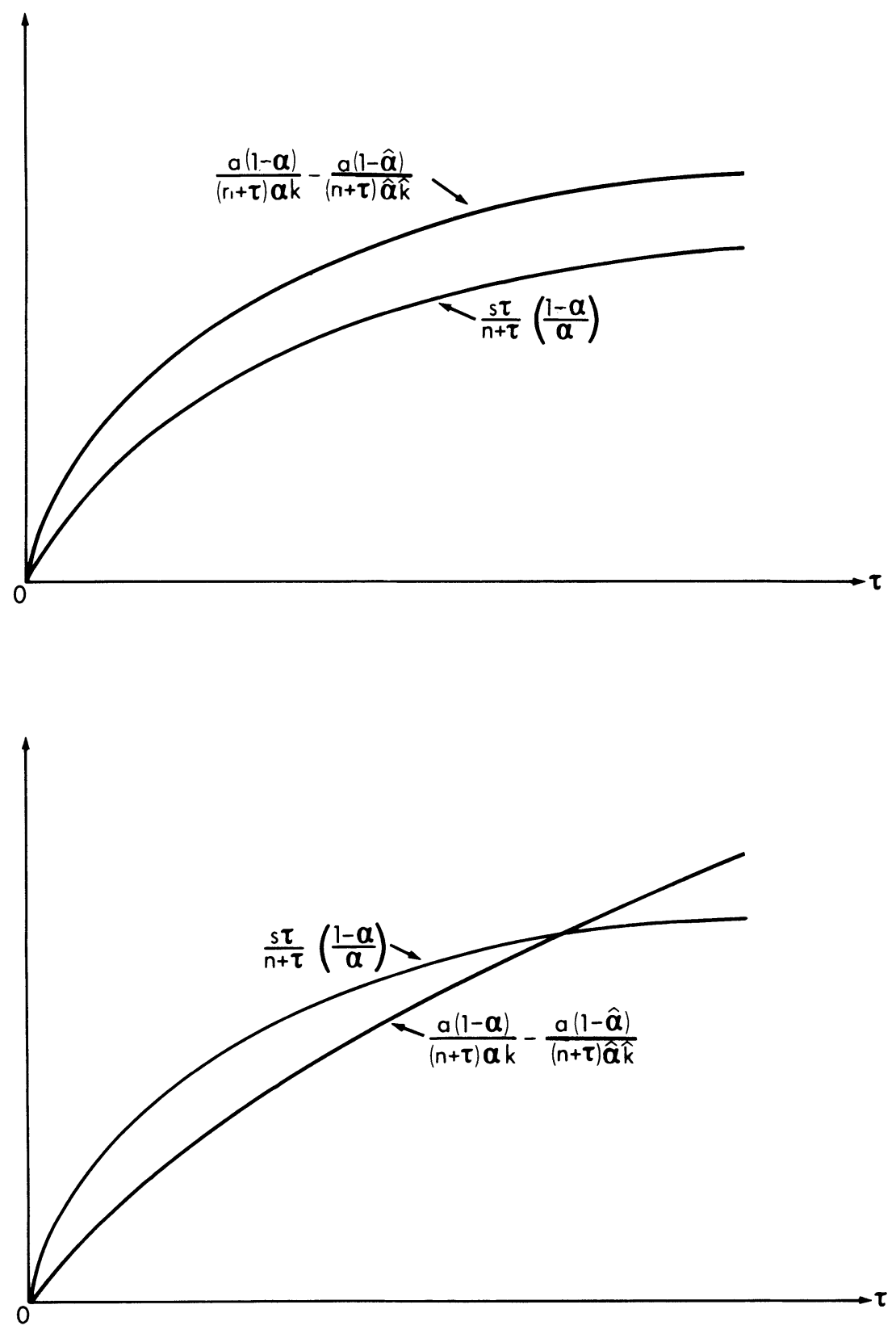

FIG. 2. $-(\alpha, \hat{k})-$ value of $\alpha$ and $k$ at $\tau=0$ 
Similarly,

But

$$
\frac{d \gamma_{y}}{d \tau} \gtrless 0 \text { as } \frac{d\{[s \tau(1-\alpha)] /[(n+\tau) \alpha]-\operatorname{ar} /[\bar{w}(n+\tau)]\}}{d \tau} \lessgtr 0 .
$$

$$
\begin{aligned}
\frac{d\left[\frac{s \tau(1-\alpha)}{(n+\tau) \alpha}-\frac{a r}{\overline{\bar{w}}(n+\tau)}\right]}{d^{\bar{k}}} & =\frac{n s(1-\alpha)}{(n+\tau)^{2} \alpha}+\frac{a r}{\overline{\bar{w}}(n+\tau)^{2}} \\
+\frac{\tau(1-\alpha)}{(n+\tau) \alpha} \frac{d s}{d \tau} & >0 .
\end{aligned}
$$

Thus the "balanced growth path" effects-keeping $k$ constant-are as expected. Inheritance taxation does reduce inequality.

\section{A Two-Class Model}

In a two-class model of income distribution of the kind proposed by Passinetti, an inheritance tax has an even greater likelihood (if compensating actions are not taken by the government) to increase the degree of inequality.

In such a model, there are two classes: a capitalist class with a high savings rate, given by $s_{c}$, and a working class with a lower savings rate, $s_{w}$. The differential equations governing the accumulation of capitalists' capital, $k_{c}$, and workers' capital, $k_{w}$, are

$$
\begin{gathered}
\dot{k}_{c}=s_{c} r k_{c}-n k_{c}, \\
\dot{k}_{w}=s_{w}\left(w+r k_{w}\right)-n k_{w} .
\end{gathered}
$$

The imposition of inheritance taxes alters these equations to read

$$
\begin{aligned}
& \dot{k}_{c}=s_{c} k_{c} r-(n+\tau) k_{c}, \\
& \dot{k}_{w}=s_{w}\left(w+r k_{w}+k \tau\right)-(n+\tau) k_{w},
\end{aligned}
$$

where we have implicitly assumed that all the proceeds of the inheritance tax are redistributed to the workers.

The steady-state rate of interest is thus given by

$$
r=\frac{n+\tau}{s_{c}}
$$

and from $(19 b)$ we can solve the steady-state ratio of workers' capital to aggregate capital:

$$
\begin{aligned}
{\left[s_{w} r-(n+\tau)\right] \frac{k_{w}}{k}+\frac{s_{w} \alpha r}{1-\alpha}+s_{w} \tau=} & \left(\frac{s_{w}}{s_{c}}-1\right)(n+\tau) \frac{k_{w}}{k} \\
& +\frac{s_{w} \alpha(n+\tau)}{s_{c}(1-\alpha)}+s_{w} \tau-0,
\end{aligned}
$$


or

$$
\begin{aligned}
\frac{k_{w}}{k} & =\left(\frac{s_{w} s_{c} \tau}{n+\tau}+\frac{s_{w} \alpha}{1-\alpha}\right) / s_{c}-s_{w} \\
\frac{d k_{w} / k}{d \tau_{\mid \tau=0}} & =\left(\frac{\sigma-1}{1-\alpha}+s_{c}\right) \frac{s_{w}}{n\left(s_{c}-s_{w}\right)}<0
\end{aligned}
$$

if $\sigma<1-(1-\alpha) s_{c}$. Thus, for low values of the elasticity of substitution, the proportion of capital owned by workers is reduced as a result of inheritance taxation. This in turn implies that the share of income of capitalists

$$
\frac{r\left(k-k_{w}\right)}{f}=(1-\alpha)\left(1-\frac{k_{w}}{k}\right)
$$

is increased. Indeed, the critical condition for the share of capitalists' income to increase is that

$$
\begin{gathered}
\left.\frac{d\left\{1-\alpha-\left[(1-\alpha) s_{w} s_{c} \tau\right] /\left[(n+\tau)\left(s_{c}-s_{w}\right)\right]-\left(s_{w} \alpha\right) /\left(s_{c}-s_{w}\right)\right\}}{d \tau}\right|_{\tau=0} \\
=\left[-\alpha^{\prime} \frac{d k}{d \tau}-\frac{(1-\alpha) s_{w}}{n}\right] \frac{s_{c}}{\left(s_{c}-s_{w}\right)} \\
=\left[(1-\sigma)-s_{w}\right] \frac{(1-\alpha) s_{c}}{\left(s_{c}-s_{w}\right) n}>0,
\end{gathered}
$$

that is, $\sigma<1-s_{w}$.

Finally, note that asymptotically, a proportional inheritance tax has no effect on the distribution of wealth among the capitalists, and asymptotically all workers have the same per capita income and capital stock; hence, an increase in the inequality of the share of capital or income accruing to the capitalist class unambiguously increases the degree of inequality in the economy.

This model provides an extreme case of the shifting of the tax, resulting in effects counter to those originally intended.

\section{The Distribution of Consumption}

It is not clear, however, whether we are ultimately interested in the inequality of the distribution of income or wealth; in some sense, the relevant variable is consumption. Under certain circumstances, the inheritance tax may actually lead to an increase in the inequality of consumption.

This is the case if the conventional adage of "from rags to riches to rags in three generations" were correct, for the effect of inheritances in 
that case is to spread the consumption of the productive antecedent over three generations; disallowing inheritances would have forced the antecedent to consume the entire amount himself.

Within a generation, there is little incentive for an individual to transfer wealth to an individual, even a relative, who is better off than he is. Most gifts are thus ambiguously equality increasing, in the sense discussed by Atkinson (1970) and Rothschild and Stiglitz (1973). It is clear that within a given generation, taxing such voluntary redistributions might well increase the degree of inequality, and certainly forbidding them would.

Similarly, it would seem that one of the motivations of parents in leaving bequests to their children is that parents who are both able (have a high wage) may, if they believe in the process of regression toward the mean, expect their children (on average) to be less able than they are. Thus, if their children's welfare enters their utility function, they will make a transfer payment to their child. On average, it is clear that this is inequality reducing, but under certain circumstances I can make an even stronger statement. I can show that, if the rate of interest is zero, inequality in the distribution of consumption, as measured by the range of the distribution, is unambiguously reduced as a result of inheritance.

To see this, assume that the bequest function $B(w, c)$ is a monotone increasing function of wage and inherited capital: $B_{w} \geq 0, B_{c} \geq 0$, but that the marginal propensity to give a bequest as inherited capital or wages increases is less than unity: $B_{w}<1, B_{c}<1$ (this condition is required for stability). Assume, moreover, that $B\left(w_{\min }, 0\right)=0$. Someone who is at the minimum wage and inherits no capital knows that all of his heirs will be at least as well off as he and hence leaves nothing to them. Then consumption is just $C=w+c-B(w, c)$, where $C$ is the level of consumption.

In steady state, the maximum value of $C$ is that attained if for an infinite number of generations all individuals in a given family line had the maximum $w, w_{\max }$; accumulation for such a family is given by $\dot{c}=B\left(w_{\max }, c\right)-c-n c$, which can be solved for the maximum value of $c, c_{\max }, B\left(w_{\max }, c_{\max }\right)=c_{\max }(1+n)$. Note that when $w=w_{\max }$ and $c=c_{\max }, C=w-n c<w_{\max }$. But $\partial C / \partial w=1-B_{w}>0, \partial C / \partial c=1$ - $B_{c}>0$. Hence $C(w, c)<C\left(w_{\max }, c_{\max }\right)<w_{\max }$. Similarly, it can be shown that $\min C(w, c)=w_{\min }$, establishing the desired result that inheritance reduces the range of the distribution of consumption. Figure 3 illustrates the steady-state range of $C$.

If there are only two groups in the population, not only is the range reduced by inheritance, but each high-wage individual has his consumption reduced, and every low-wage individual has his consumption increased. Regression toward the mean in that case simply means that there is a finite probability of a parent of one type having a child of the other. 


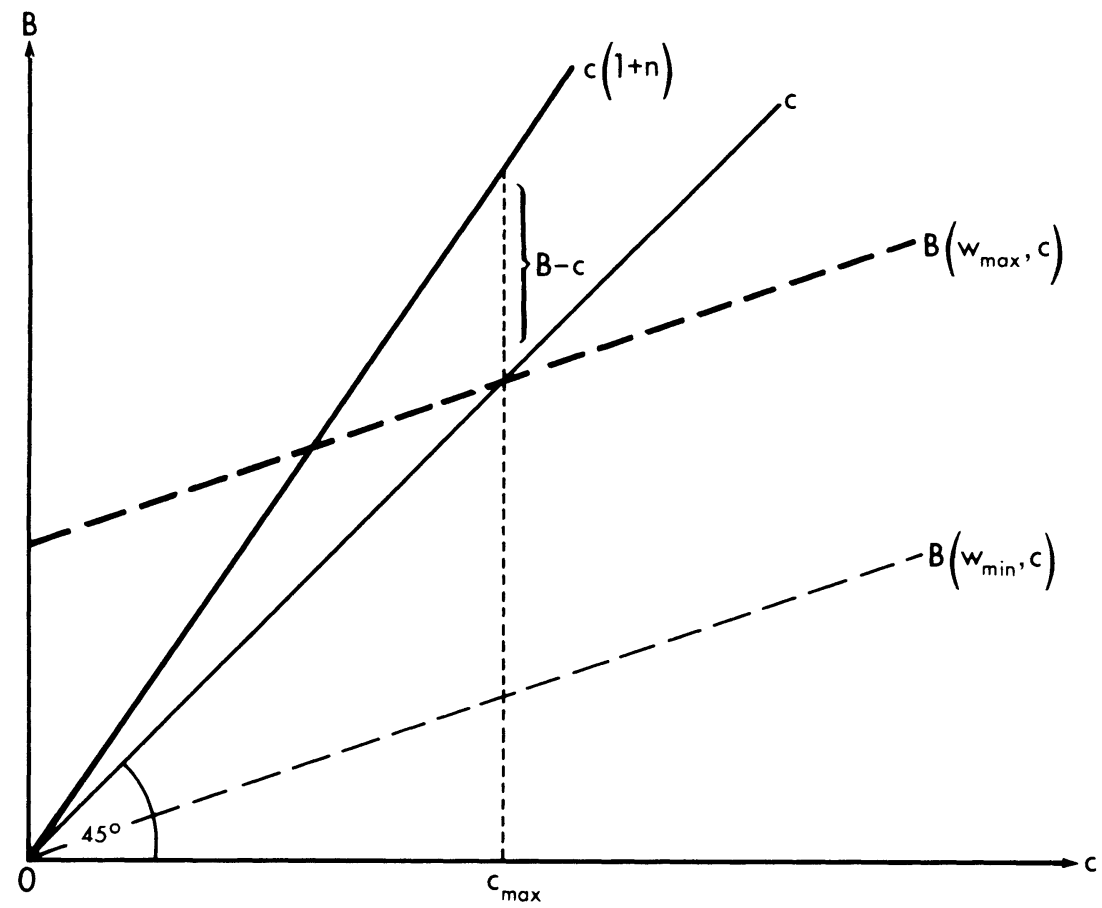

FIG. 3

Then a parent of the more able who inherits less than a critical amount $c_{\max }$ will leave to his children (assuming for simplicity that he does not know their ability at the time of bequest) an amount in excess of the amount that he has inherited, that is, he consumes less than his own wage income. A parent of the more-able type who inherits more than $c_{\max }$ will consume out of his inheritance, but in steady state no one will ever inherit more than $c_{\max }$. Thus, all individuals of the more-able type consume an amount less than or equal to their wage incomes, that is, the income that they would have consumed if inheritances were not allowed. The same argument establishes that all individuals of the lower ability group consume an amount equal to or more than their consumption if inheritances were not allowed. Thus putting a prohibitive tax on inheritances would be unambiguously inequality increasing.

A fuller analysis of the effect of inheritance taxation on the distribution of consumption requires a more detailed specification of the stochastic process generating income. In Stiglitz (1977) it is shown that, provided $r$ is not too large, inheritances are inequality reducing.

\section{Distortions of the Estate Tax on the Form of Transfer}

I discussed briefly earlier the incentive effects of the estate tax on the total amount of bequests left. But there is a further effect of the tax-on 
the form which bequests take. This distortion arises because of the inability to monitor all transfers. In particular, by giving his child human capital, he transfers wealth to his child without paying inheritance or gift taxes. Since much of the acquisition of human capital does not occur within the market sector, it would be virtually impossible to tax such transfers. To the extent that this offsets effects associated with imperfect capital markets for human capital, the distortion may be desirable; it may, however, lead to excessive expenditures on human capital relative to physical capital. The ability of parents to transfer wealth to their children in the form of human capital also limits the ability to equalize incomes through an inheritance tax. Finally, differences in wage incomes may be more invidious (in terms of individuals' views of themselves, their status, etc.) than differences in capital income.

A further effect of the tax is to change the composition of physical assets. Under certain not implausible circumstances, both of these allocative effects may result in the long-run distribution of income and wealth becoming more unequal as a result of the imposition of a tax (see Stiglitz 1977).

\section{Concluding Comments}

In this article I have focused on several aspects of the economics of estate taxes that have received perhaps too little attention in recent discussions. These taxes may not lead to the reduction in inequality which their proponents desire, but rather may increase the degree of inequality. The importance of these considerations depends not only on the values of certain economic parameters, which I have identified in my earlier discussion, but also on the importance ascribed to these economic considerations relative to the noneconomic considerations. Accumulations of wealth may, it is argued, lead to accumulations of political power and affect the nature of our political processes. Opponents of estate taxes are concerned with the ethical grounds for restricting this particular class of choices of individuals. They ask, Why should parents who do not wish to leave wealth to their children but prefer to consume it themselves restrict the ability of parents who do wish to leave wealth to their children? Although these ethical and political questions may in the final analysis be more important in determining policies toward inheritances, it is at least worth noting the important economic effects of such policies.

\section{References}

Atkinson, A. B. “On the Measurement of Inequality." J. Econ. Theory 2 (1970): 244-63.

Rothschild, M., and Stiglitz, Joseph E. "Some Further Results on the Measurement of Inequality." J. Econ. Theory 5 (April 1973): 188-204. 
Stiglitz, Joseph E. "Distribution of Income and Wealth among Individuals." Econometrica 37 (July 1969) : 382-97.

. "Equality, Taxation and Inheritance." Paper presented at the IEA Conference on Income Distribution, Noordwijk-an-Zee, Netherlands, April 1977. 